\title{
Association between ICS use and risk of hyperglycemia in COPD patients: systematic review and meta-analysis
}

\author{
Xiaofeng Pu ${ }^{1 \dagger}$, Liang Liư ${ }^{2 \dagger}$, Bimin Feng ${ }^{2}$, Zhengji Zhang ${ }^{1}$ and Guojun Wang ${ }^{1 *}$
}

\begin{abstract}
Background: The effect of inhaled corticosteroids (ICS) on risk of hyperglycemia in patients with chronic obstructive pulmonary disease (COPD) remains ambiguous. The aim of this study is to evaluate the association between ICS use and the incidence of hyperglycemia related adverse effects in COPD patients.

Methods: Medline/PubMed, Embase, the Cochrane Central Register of Controlled Trials (CENTRAL), and ClinicalTrials. gov were searched from inception to 25 May 2020. Randomized controlled trials (RCTs) of ICS versus control (non-ICS) treatment for COPD patients reporting on risk of hyperglycemia were included. The Mantel-Haenszel method with fixed-effects modeling was used to calculate pooled relative risks (RRs) and 95\% confidence intervals (Cls).

Results: Seventeen RCTs with 43,430 subjects were included in the meta-analysis. Pooled results suggested that there was no statistically significant difference in the risk of hyperglycemia between the ICS group and the control group (RR 1.02, 95\% Cl 0.90-1.16, $\mathrm{P}=0.76$ ). In addition, no significant difference was noted in the effect on glucose level (RR 1.20,95\% Cl 0.79-1.82, $\mathrm{P}=0.40$ ), risk of diabetes progression ( $R R 0.84,95 \% \mathrm{Cl} 0.20-3.51, \mathrm{P}=0.81$ ) and new onset diabetes mellitus (RR 1.0, 95\% Cl 0.88-1.15, $\mathrm{P}=0.95$ ) between the ICS group and the control group. These findings also were consistent across all subgroup analyses.

Conclusions: Use of ICS does not have an effect on the blood glucose and is not associated with the risk of new onset diabetes mellitus and diabetes progression in patients with COPD. Further RCTs exploring the association between ICS use and risk of hyperglycemia in COPD patients are still needed to verify our results of this analysis.
\end{abstract}

Keywords: COPD, Inhaled corticosteroids, Randomised controlled trials, Meta-analysis

\section{Background}

Chronic obstructive pulmonary disease (COPD) is a universal progressive inflammatory disease that is characterized by persistent respiratory symptoms and airflow limitation [1]. Exacerbations of COPD are important events in the course of the disease that often lead to an increased risk of death and have an impact on patients'

\footnotetext{
*Correspondence: renren333@126.com

${ }^{+}$Xiaofeng Pu and Liang Liu have contributed equally to this work

1 Department of Pharmacy, The Affiliated Hospital of Southwest Medical University, 25 Taiping Street, Luzhou 646000, Sichuan, China

Full list of author information is available at the end of the article
}

lung function and health status [2]. Long-acting bronchodilators, including $\beta 2$ agonists (LABA) and muscarinic antagonists (LAMA), were recommended as the standard care to reduce the risk of severe exacerbations and to improve symptoms in patients with COPD [3]. In addition, Inhaled corticosteroids (ICS) treatment is suggested to only in Stage-D COPD with eosinophilia (Blood eosinophils $>300$ cells $/ \mu \mathrm{l})$, according to GOLD 2020 guideline [4]. The place of ICS in the standard care of COPD is now much limited.

In the real-world environment, doctors frequently ignore clinical guidelines and the severity of the disease, and overusing ICS in COPD patients is common $[5,6]$. original author(s) and the source, provide a link to the Creative Commons licence, and indicate if changes were made. The images or other third party material in this article are included in the article's Creative Commons licence, unless indicated otherwise in a credit line to the material. If material is not included in the article's Creative Commons licence and your intended use is not permitted by statutory regulation or exceeds the permitted use, you will need to obtain permission directly from the copyright holder. To view a copy of this licence, visit http://creativecommons.org/licenses/by/4.0/. The Creative Commons Public Domain Dedication waiver (http://creativeco mmons.org/publicdomain/zero/1.0/) applies to the data made available in this article, unless otherwise stated in a credit line to the data. 
Although the treatment containing ICS has a role in dual and triple therapy for COPD to reduce the risk of exacerbations and improve symptoms, ICS-related safety issues remain a serious concern. Treatment with ICS is associated with several adverse effects, such as pneumonia, fractures, and upper respiratory tract infection [7-9]. In addition, some observational studies revealed increased risk of onset and progression of diabetes, especially when higher ICS doses were utilized [10, 11]. However, some other studies did not indicate an increased risk of diabetes among users of ICS $[12,13]$. Herein, there is currently no consensus on the association between ICS therapy and risk of hyperglycemia and diabetes.

A previous retrospective analysis evaluated whether there was an increased risk of new onset diabetes mellitus or hyperglycemia among patients with asthma or COPD treated with ICS in randomized controlled trials (RCTs), and found ICS therapy was not associated with increased risk of hyperglycemia or new onset diabetes mellitus [14]. However, the mean follow-up period of this analysis was only 217 days after the onset of ICS use and it published in 2012 [14]. Recently there are numbers of RCTs which investigate the treatment with ICS in COPD patients and report the adverse effects of rise in blood glucose levels, new onset diabetes mellitus and diabetes progression [15-19]. However, the incidence of these hyperglycemia related adverse effects are not consistent across the results. In addition, there is currently no meta-analysis to explore the association between ICS therapy and risk of hyperglycemia. Therefore, we perform this meta-analysis including all RCTs which record the hyperglycemia related adverse effects (rise in blood glucose levels, new onset diabetes mellitus and diabetes progression) among COPD patients with the ICS therapy to investigate whether treatment with ICS increase the risk of hyperglycemia in COPD patients.

\section{Methods}

\section{Protocol and guidance}

The study protocol was registered in the International Database of Prospectively Registered Systematic Reviews (PROSPERO; Registration No. CRD42020185288), and it was conducted in accordance with Preferred Reporting Items for Systematic Reviews and Meta-Analysis (PRISMA) statement [20]. An additional table file shows this in more detail [see Additional file 1: Table S1].

\section{Search strategy}

We searched Medline/PubMed, Embase, the Cochrane Central Register of Controlled Trials (CENTRAL), from inception to 25 May 2020. We also searched ClinicalTrials.gov to identify ongoing or unpublished eligible trials. The geographic area and language were not restricted.
Disagreements between two reviewers were resolved by discussion. The detailed search strategy was shown in an additional table file [see Additional file 2: Table S2].

\section{Inclusion criteria}

The inclusion criteria were described below: (1) patients were diagnosed with COPD of any severity; (2) intervention was treatment containing ICS; (3) comparison was placebo or treatment containing non-ICS; (4) the data related to hyperglycemia were provided in the studies; (5) the type of study was randomised controlled trial (RCT).

\section{Exclusion criteria}

We excluded the studies if they were case reports, or observational studies; if the patients complicated with allergic rhinitis, pulmonary infarction, pulmonary encephalopathy, bronchial asthma, pneumoconiosis, and active tuberculosis; if studies were published in reviews, abstracts, or protocols.

\section{Assessment of risk of bias in included studies}

Two reviewers (XFP and LL) assessed the quality of each included study according to the Cochrane Handbook for Systematic Reviews of Interventions [21]. We assessed risk of bias according to the following items: random sequence generation, allocation concealment, blinding of participants and investigators, blinding of outcome assessment, incomplete outcome data, selective outcome reporting, etc. The risk of bias was assessed by two reviewers independently, and disagreements were resolved by discussion.

\section{Data extraction}

Two independent reviewers (XFP and LL) utilized a standard data extraction form to extract data from the included RCTs. The studied data were pooled from the separate treatment arms when RCTs had more than two arms. The data were extracted from original articles and checked for accuracy by two reviewers.

\section{Data analysis}

Herein, Stata 16.0 software was used to perform statistical analysis. We used risk ratios (RR) and their associated $95 \%$ confidence intervals (CIs) to assess outcomes, and considered a P value less than 0.05 to be statistically significant. Statistical heterogeneity was assessed using the $\mathrm{I}^{2}$ test, and the heterogeneity was considered significant when $\mathrm{I}^{2} \geq 50 \%$. A random effects model was used when significant heterogeneity was present; otherwise, a fixed effects model was utilized. The publication bias was assessed by visually inspecting the funnel plot and was detected via the Egger test, the Begg test, and the Harbord test. 


\section{Subgroup analyses and sensitivity analyses}

The subgroup analyses were performed to test the influence of daily dose, duration. When significant heterogeneity was observed in pooled effect estimates, the sensitivity analyses were used by removing one study at a time to explore whether the heterogeneity was significantly reduced.

\section{Results}

Eligible studies and study characteristics

Of the 3034 studies we retrieved from the aforementioned databases, we included 17 eligible trials [15-19, 22-33] in the final meta-analysis (Fig. 1). Detailed characteristics included in RCTs are presented in Table 1. The 17 included RCTs enrolled 43,430 subjects, of whom

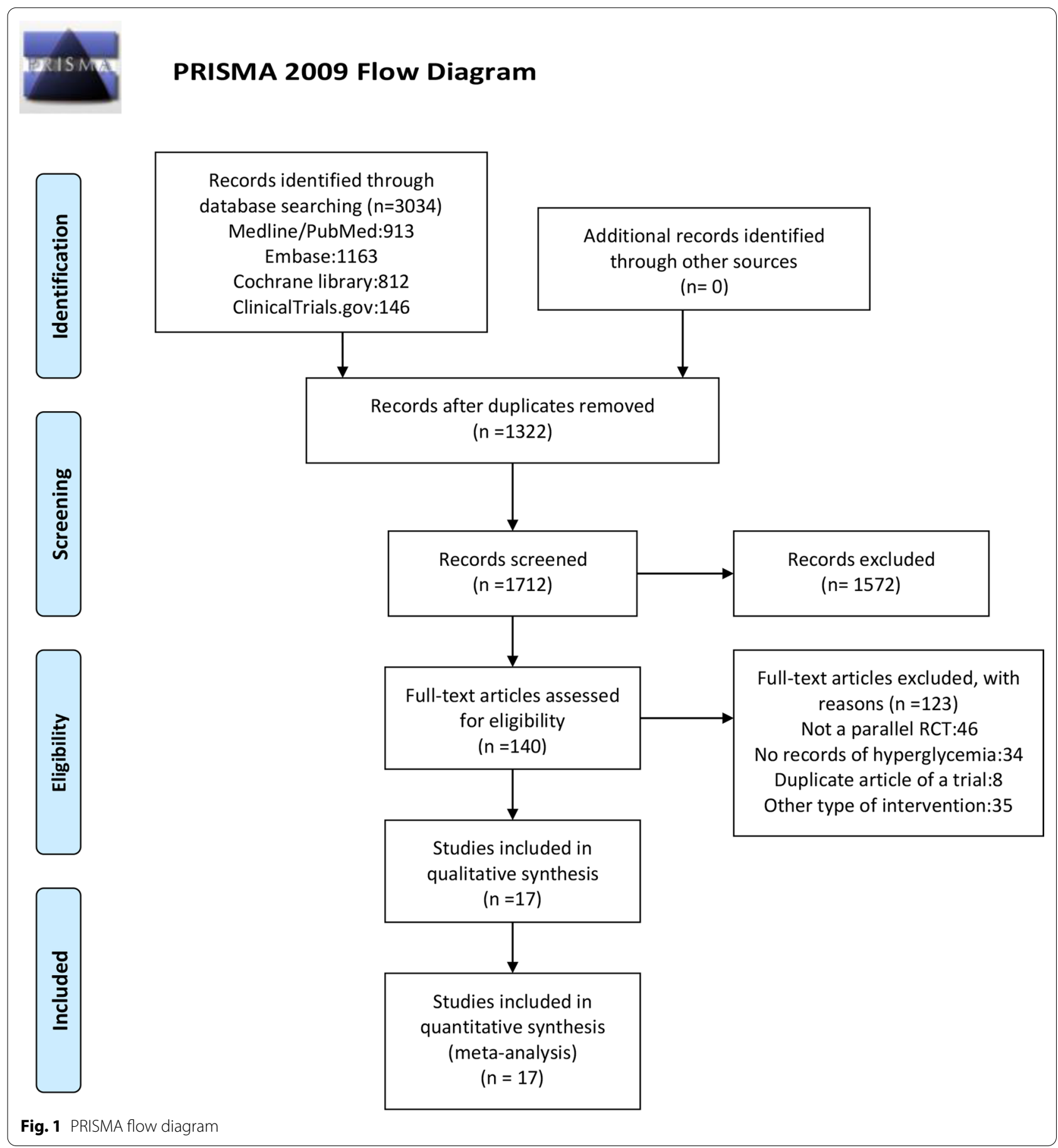


Table 1 Characteristics of included studies

\begin{tabular}{|c|c|c|c|c|c|c|}
\hline Study & Drug & Subjects, $\mathrm{N}$ & Male (\%) & Mean age, years (SD) & $\begin{array}{l}\text { Mean \% } \\
\text { predicted FEV1 } \\
\text { (SD) }\end{array}$ & $\begin{array}{l}\text { Treatment } \\
\text { duration, } \\
\text { weeks }\end{array}$ \\
\hline \multirow[t]{2}{*}{ Asai et al. (2015) [17] } & SFC 50/250 $\mu \mathrm{g}$, bid & 26 & $25(96)$ & $64.7(9.31)$ & $1.983(0.5797)$ & 12 \\
\hline & Placebo & 26 & $26(100)$ & $62.2(8.06)$ & $2.044(0.4638)$ & \\
\hline \multirow{2}{*}{ Zhong et al. (2015) [22] } & QVA149 110/50 $\mu \mathrm{g}$, qd & 372 & $341(91.7)$ & $64.8(7.8)$ & $51.6(12.8)$ & 26 \\
\hline & SFC 50/500 $\mu \mathrm{g}, \mathrm{bid}$ & 369 & $331(89.7)$ & $65.3(7.9)$ & $52.0(12.9)$ & \\
\hline \multirow[t]{3}{*}{ Bhatt et al. (2017) [15] } & FF/NI 100/25 $\mu \mathrm{g}$, qd & 141 & $104(77)$ & $68.5(8.0)$ & $1.29(0.43)$ & 24 \\
\hline & VI $25 \mu \mathrm{g}$, qd & 158 & $118(77)$ & $68.7(7.7)$ & $1.24(0.42)$ & \\
\hline & Placebo & 145 & $119(84)$ & $68.2(8.1)$ & $1.30(0.44)$ & \\
\hline \multirow[t]{4}{*}{ Dransfield et al. (2013) [16] } & $\mathrm{Vl}, 25 \mu \mathrm{g}, \mathrm{qd}$ & 818 & $474(58)$ & $63.6(9.4)$ & $1.3(0.5)$ & 52 \\
\hline & FF/NI 50/25 $\mu \mathrm{g}$, qd & 820 & $476(58)$ & $63.6(9.4)$ & $1 \cdot 3(0.5)$ & \\
\hline & FF/VI 100/25 $\mu \mathrm{g}$, qd & 806 & $453(56)$ & $63 \cdot 8(9 \cdot 2)$ & $1.3(0.5)$ & \\
\hline & FF/NI 200/25 $\mu \mathrm{g}$, qd & 811 & $467(57)$ & $63.7(9.0)$ & $1.3(0.5)$ & \\
\hline \multirow[t]{5}{*}{ Kerwin et al. (2013) [23] } & FF $100 \mu \mathrm{g}$, qd & 206 & $132(64)$ & $62.7(9.47)$ & $46.9(12.73)$ & 24 \\
\hline & VI $25 \mu \mathrm{g}$, qd & 205 & $140(68)$ & $63.4(9.58)$ & $49.9(12.05)$ & \\
\hline & FF/NI 50/25 $\mu \mathrm{g}$, qd & 206 & $135(66)$ & $62.8(9.13)$ & $48.4(12.66)$ & \\
\hline & FF/VI 100/25 $\mu \mathrm{g}$, qd & 206 & $137(67)$ & $62.3(8.49)$ & $47.8(12.28)$ & \\
\hline & Placebo & 207 & $141(68)$ & $62.1(8.80)$ & $48.5(12.46)$ & \\
\hline \multirow[t]{2}{*}{ Maltais et al. (2002) [24] } & BUD 2 mg q6h & 71 & $57(80.2)$ & $69.1(8.7)$ & $1.14(0.45)$ & 1.5 \\
\hline & Placebo & 66 & $53(80.3)$ & $70.4(8.9)$ & $1.13(0.44)$ & \\
\hline \multirow[t]{6}{*}{ Martinez et al. (2013) [25] } & FF $100 \mu \mathrm{g}, \mathrm{qd}$ & 204 & $150(74)$ & $61.8(8.28)$ & $48.4(12.17)$ & 24 \\
\hline & FF $200 \mu \mathrm{g}, \mathrm{qd}$ & 203 & $151(74)$ & $61.8(9.02)$ & $47.1(11.98)$ & \\
\hline & VI $25 \mu \mathrm{g}, \mathrm{qd}$ & 203 & $151(74)$ & $61.2(8.62)$ & $48.5(12.89)$ & \\
\hline & FF/NI 100/25 $\mu \mathrm{g}$, qd & 204 & $144(71)$ & $61.9(8.79)$ & $48.1(12.85)$ & \\
\hline & FF/NI 200/25 $\mu \mathrm{g}, \mathrm{qd}$ & 205 & $137(67)$ & $61.1(8.58)$ & $47.1(12.76)$ & \\
\hline & Placebo & 205 & $152(74)$ & $61.9(8.14)$ & $48.3(12.71)$ & \\
\hline \multirow[t]{3}{*}{ Sharafkhaneh et al. (2012) [26] } & BUD/FM 320/9 $\mu \mathrm{g}$ bid & 407 & $262(64.4)$ & $63.8(9.4)$ & $37.9(11.8)$ & 48 \\
\hline & BUD/FM $160 / 9 \mu \mathrm{g}$ bid & 408 & $264(64.7)$ & $62.8(9.2)$ & $37.6(11.6)$ & \\
\hline & FM $9 \mu \mathrm{g}$ bid & 403 & $229(56.8)$ & $62.5(9.4)$ & $37.5(12.4)$ & \\
\hline \multirow[t]{2}{*}{ Siler et al. (2016) [27] } & FF/NI 100/25 $\mu \mathrm{g}$, qd & 806 & $605(75)$ & $65.3(8.58)$ & $50.3(10.33)$ & 12 \\
\hline & VI $25 \mu \mathrm{g}, \mathrm{qd}$ & 814 & $625(77)$ & $65.4(9.02)$ & $50.5(10.33)$ & \\
\hline \multirow{2}{*}{ Vogelmeier et al. (2013) [28] } & QVA149 110/50 $\mu \mathrm{g}$, qd & 258 & $181(70.2)$ & $63 \cdot 2(8 \cdot 2)$ & $60 \cdot 5(10 \cdot 5)$ & 26 \\
\hline & SFC 50/500 $\mu \mathrm{g}$, bid & 264 & $189(71.6)$ & $63.4(7 \cdot 7)$ & $60 \cdot 0(10 \cdot 7)$ & \\
\hline \multirow[t]{4}{*}{ Vestbo et al. (2016) [29] } & FF $100 \mu \mathrm{g}$, qd & 4157 & $3053(73.8)$ & $65(8)$ & $59 \cdot 6(6 \cdot 1)$ & 96 \\
\hline & VI $25 \mu \mathrm{g}$, qd & 4140 & $3053(74.1)$ & $65(8)$ & $59 \cdot 7(6 \cdot 1)$ & \\
\hline & FF/VI 100/25 $\mu \mathrm{g}$, qd & 4140 & $3112(75.5)$ & $65(8)$ & $59 \cdot 7(6 \cdot 1)$ & \\
\hline & Placebo & 4131 & $3071(74.7)$ & $65(8)$ & $59.7(6 \cdot 1)$ & \\
\hline \multirow[t]{2}{*}{ Wedzicha et al. (2014) [30] } & BDP/FOR 100/6 $\mu \mathrm{g} \times 2$, bid & 601 & $408(69)$ & $64.6(8.6)$ & $41.9(6.0)$ & 48 \\
\hline & FOR $12 \mu \mathrm{g}$, bid & 596 & $410(69)$ & $63.9(8.6)$ & $41.6(6.0)$ & \\
\hline \multirow[t]{4}{*}{ Zheng et al. (2014) [31] } & FF/NI 50/25 $\mu \mathrm{g}$, qd & 160 & $144(90)$ & $65.2(8.41)$ & $47.5(14.21)$ & 24 \\
\hline & FF/VI 100/25 $\mu \mathrm{g}$, qd & 161 & $149(93)$ & $65.1(9.19)$ & $49.6(13.19)$ & \\
\hline & 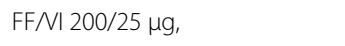 & 160 & $145(91)$ & $62.7(8.65)$ & $48.2(13.63)$ & \\
\hline & Placebo & 162 & $146(90)$ & $64.7(8.78)$ & $48.6(13.39)$ & \\
\hline \multirow[t]{3}{*}{ Lipson et al. (2018) [18] } & FF/UMEC/VI 100/62.5/25 $\mu \mathrm{g}$, qd & 4151 & $2766(66.6)$ & $65.3(8.2)$ & $45.7(15.0)$ & 52 \\
\hline & FF/VI 100/25 $\mu \mathrm{g}$, qd & 4134 & $2748(66.5)$ & $65.3(8.3)$ & $45.5(14.8)$ & \\
\hline & UMECN $162.5 / 25 \mu \mathrm{g}$, qd & 2070 & $1356(65.5)$ & $65.2(8.3)$ & $45.4(14.7)$ & \\
\hline \multirow[t]{2}{*}{ NCT00857766 [32] } & FSC 250/50 $\mu \mathrm{g}$, bid & 123 & $68(55.3)$ & $63.6(8.92)$ & & 16 \\
\hline & Matching Placebo & 126 & $74(58.7)$ & $63.5(7.88)$ & & \\
\hline \multirow[t]{2}{*}{ Wedzicha et al. (2016) [19] } & QVA149 110/50 $\mu \mathrm{g}$, qd & 1678 & $1299(77.3)$ & $64.6(7.9)$ & $44.0(9.5)$ & 52 \\
\hline & SFC 50/500 $\mu \mathrm{g}$, bid & 1680 & $1258(74.8)$ & $64.5(7.7)$ & $44.1(9.4)$ & \\
\hline \multirow[t]{2}{*}{ NCT03474081 [33] } & FF/UMECNI 100/62.5/25 $\mu \mathrm{g}$, qd & 400 & $274(68.5)$ & $66.2(8.08)$ & & 12 \\
\hline & Tiotropium $18 \mu \mathrm{g}$, qd & 399 & $269(67.3)$ & $66.1(7.78)$ & & \\
\hline
\end{tabular}


Table 1 (continued)

FF fluticasone furoate; $V I$ vilanterol; $S F C$ salmeterol/fluticasone propionate; $Q V A 149$ indacaterol/glycopyrronium; $B U D$ budesonide; $F M$ formoterol; $B D P / F O R$ beclomethasone dipropionate/formoterol fumarate; UMEC umeclidinium; FSC Fluticasone Propionate/Salmeterol; FEV1 forced expiratory volume in 1 second

26248received ICS treatment and 17,182 received nonICS treatment. The RCT of Bhatt et al. [15] was included in both effect on glucose level subgroup and new onset diabetes mellitus subgroup, so the total number of subjects were 43,874 (26,389 with ICS treatment,17,485 with non-ICS treatment), as show in Fig. 3. The years of publication of these RCTs ranged from 2002 to 2018 . Five studies used the low-dose ICS (fluticasone propionate $<250 \mu \mathrm{g} /$ day; budesonide $<400 \mu \mathrm{g} /$ day; beclomethasone dipropionate $<200 \mu \mathrm{g} /$ day; fluticasone furoate $<100$ ug/day) [34]. Eleven studies used the high-dose ICS (fluticasone propionate $\geq 500 \mu \mathrm{g} /$ day; budesonide $\geq 800 \mu \mathrm{g} /$ day; beclomethasone dipropionate $\geq 400 \mu \mathrm{g} /$ day; fluticasone furoate $\geq 200 \mu \mathrm{g} /$ day), and nine studies utilized medium-dose ICS.

\section{Risk of bias in included studies}

Figure 2 showed the risk of bias. Eight trials had a low risk of bias. Five trials an unclear risk for random sequence generation. Nine trials had an unclear risk for allocation concealment, because it was not described in these trials. We did not find out other sources of bias in the fifteen trials, and they were unclear in the other two trials.

\section{Use of ICS and risk of hyperglycemia}

All seventeen studies reported the adverse effects related to hyperglycemia. Among them, six studies reported the effect on glucose level, and four studies reported diabetes progression; new onset diabetes mellitus was recorded in eight studies. There was no statistically significant difference in the risk of hyperglycemia between the ICS group and the control group (RR 1.02, 95\% CI 0.90-1.16, $\mathrm{P}=0.76$; Fig. 3). No statistical heterogeneity $\left(\mathrm{I}^{2}=0 \%\right)$ was found in the pooled effect estimate. Funnel plot analysis showed no asymmetry (Fig. 4); additionally, the Egger test $(\mathrm{P}=0.99)$, Begg test $(\mathrm{P}=0.34)$, and Harbord test $(\mathrm{P}=0.86)$ detected no significant publication bias.

Six studies reported the effect on glucose level. The pooled estimate revealed no significant difference between the ICS group and the control group in the effect on glucose level (RR 1.20, 95\% CI $0.79-1.82, \mathrm{P}=0.40$; Table 2). The results were consistent across all subgroup analyses, as shown in Table 2 . The pooled RR for diabetes progression was 0.84 (95\% CI $0.20-3.51, \mathrm{P}=0.81$ ), and no statistical heterogeneity $\left(\mathrm{I}^{2}=0 \%\right)$ was noted. Eight studies recorded the new onset diabetes mellitus. There was no significant difference between the ICS group and the control group in the risk of new onset diabetes mellitus (RR 1.0, 95\% CI $0.88-1.15, \mathrm{P}=0.95)$. The results also were consistent across all subgroup analyses, as shown in Table 3.

\section{Discussion}

\section{Main findings}

This analysis showed that use of ICS did not significantly increase the risk of hyperglycemia, new onset diabetes mellitus and diabetes progression in patients with COPD. Moreover, these findings were consistent across all subgroup analyses. Dendukuri et al. [12] performed a cohort study to investigate the relationship between ICS and diabetes and their results did not indicate a significant increased risk of diabetes in COPD patients who used the ICS therapy. In a crosssectional study, the influence of corticosteroid therapy in asthma on diabetes control was assessed, and this study revealed that ICS administered in low or mild doses do not affect fasting glycemia [35]. The insulin resistance is currently considered to be associated with not only type 2 diabetes (T2D) but also type 1 diabetes [36]. Borsi et al. conducted a quasi-experimental trial to investigate insulin resistance and the effect of ICS on insulin sensitivity in asthmatic patients, and the results of this trial indicated that there is no relationship between ICS and increased insulin resistance in asthmatic patients [37]. The findings of this metaanalysis are in line with the results of previous studies, mentioned above. The systemic bio-availability of ICS is considered to be minimal, so the metabolic complications involved in ICS use might be negligible [38]. This might explain our results for the no significant difference on the risk of hyperglycemia between ICS group and control group in COPD patients. However, there were some other studies found that use of ICS did increase the risk of hyperglycemia and diabetes. Saeed et al. [11] conducted a nationwide observational cohort study and demonstrated that ICS use was associated with a moderate increase (high ICS dose: HR 1.16, CI 1.01-1.32, $\mathrm{p}=0.03$ ) in the risk of T2D in COPD patients, but only for high-dose ICS use and $B M I<30 \mathrm{~kg} / \mathrm{m}^{2}$. For the subgroup $B M I \geq 30 \mathrm{~kg} / \mathrm{m}^{2}$, all exposure groups of ICS seemed to have a lower risk of T2D events. Another cohort study showed that long-term ICS therapy and high-dose ICS (mean daily dose $\geq 500 \mu \mathrm{g}$ fluticasone propionate-equivalent) for COPD patients is associated with an increased risk of new onset diabetes and diabetes progression [10]. These studies demonstrated that there was association between high-dose ICS therapy and risk of diabetes 


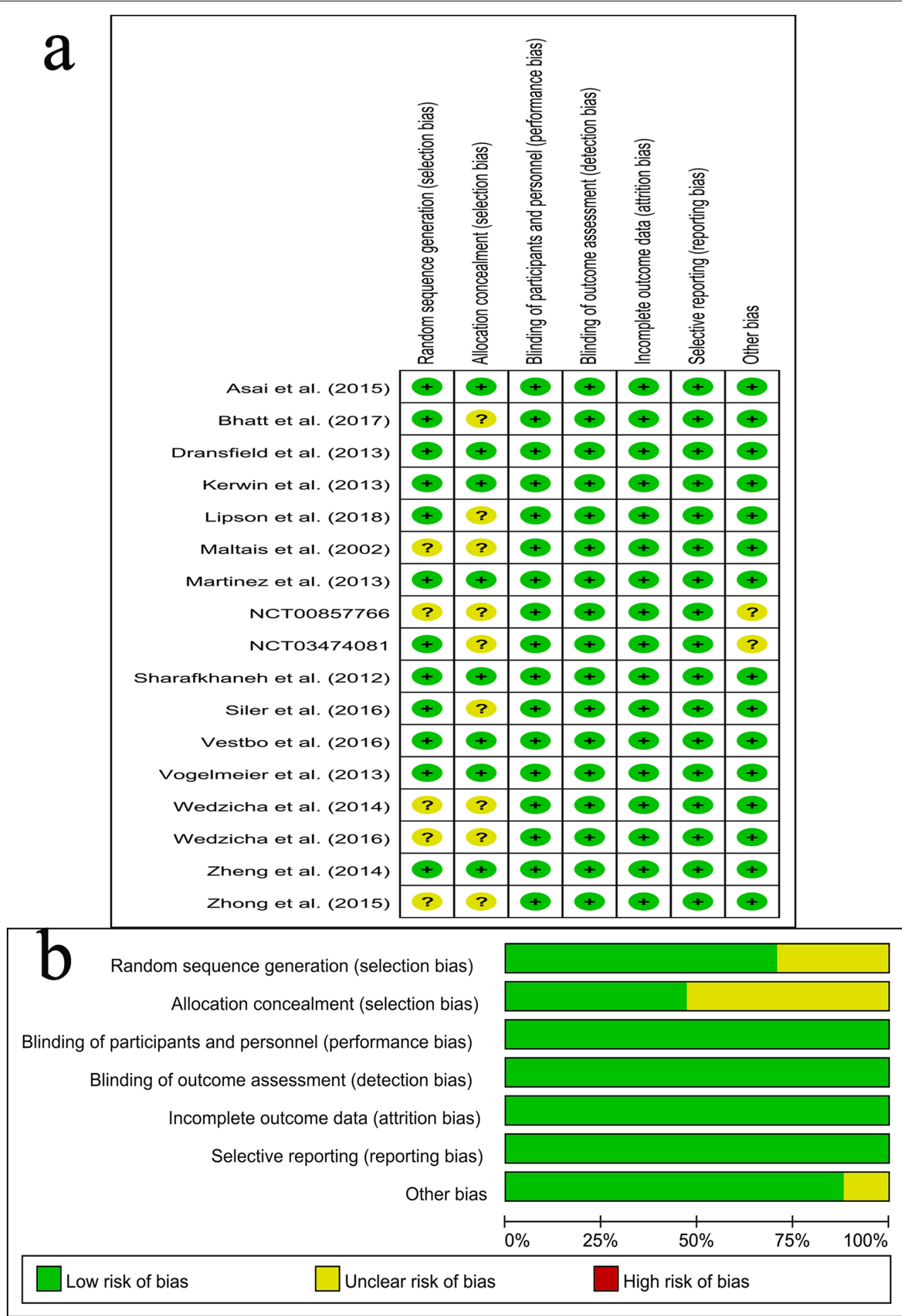

Fig. 2 a Risk of bias summary for included studies, showing each risk of bias item for every included study. b Risk of bias graph presenting each risk of bias item as percentages across all included studies 


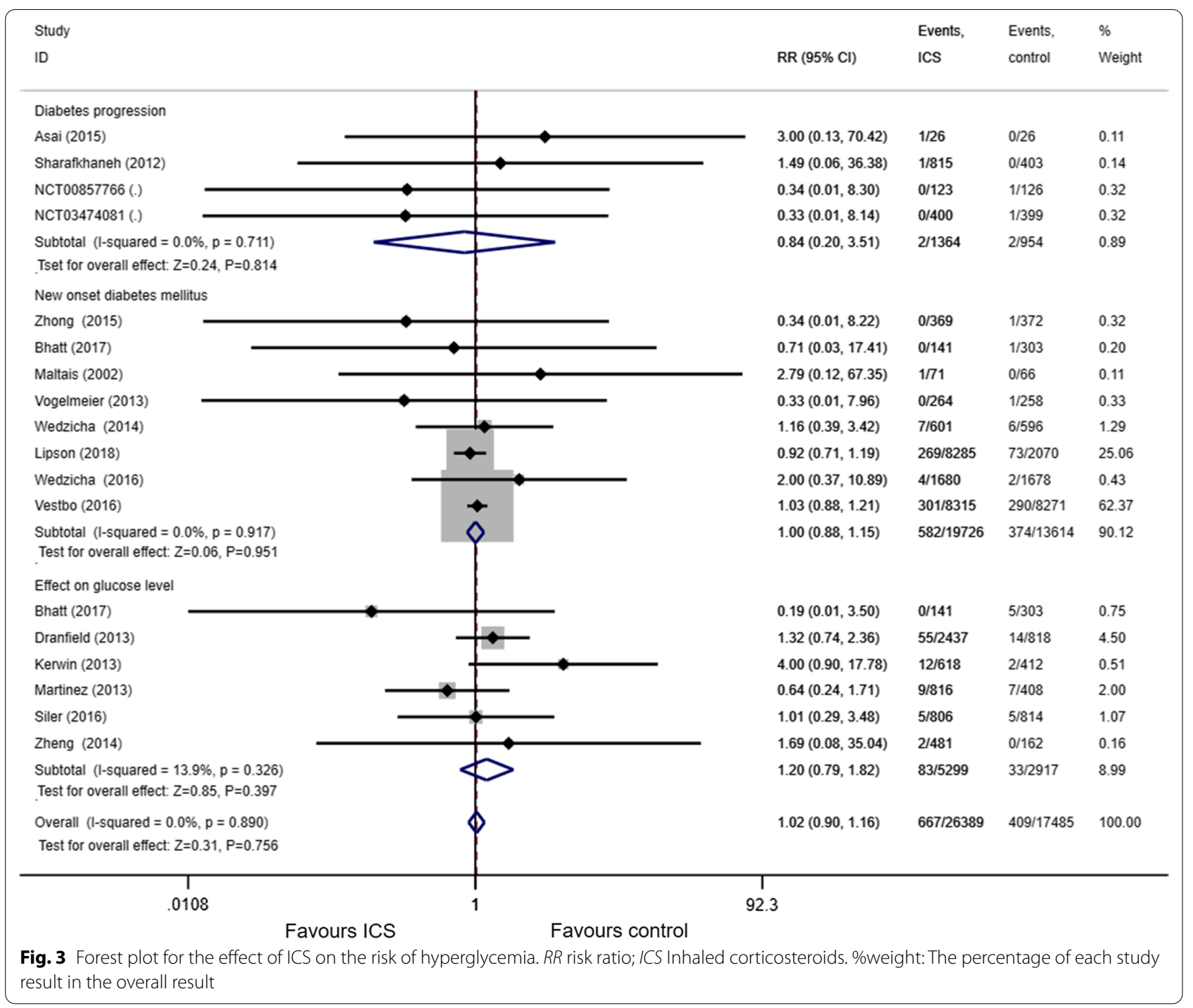

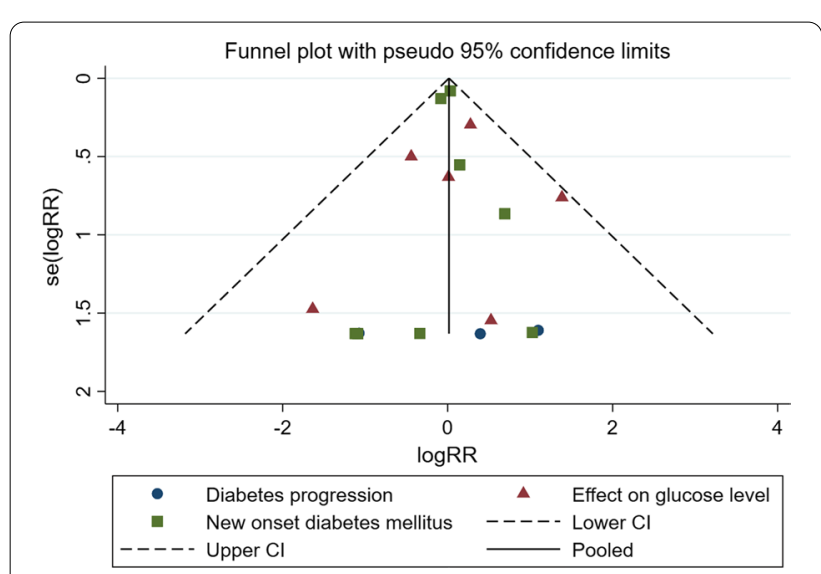

Fig. 4 Funnel plot for the effect of ICS on the risk of hyperglycemia and hyperglycemia, but moderate- and low-dose ICS groups showed no such association. Meanwhile, Dransfield et al. found that in patients with COPD, high-dose ICS therapy did not show superiority in reducing the acute exacerbations and improving the lung function compared to lower-dose ICS [16]. Our subgroup analysis results indicated the RR of the effect on glucose level in ICS vs. control increased from 1.20 to 1.38 with the ICS doses escalated. However, even for high-dose ICS group, the increase of the risk did not reach the level of statistical significance, compared to control group. Herein, use of ICS may not significantly increase the risk of new onset diabetes mellitus and diabetes progression, and not have an effect on the blood glucose. Further RCTs exploring the association between ICS use and risk of hyperglycemia are still needed to verify our results of this analysis. 
Table 2 Subgroup analyses for the effect on the blood glucose

\begin{tabular}{|c|c|c|c|c|c|}
\hline Subgroup title & No of trials & No of participants & Risk ratio $(95 \% \mathrm{CI})$ & PValue & $\mathrm{I}^{2}(\%)$ \\
\hline Overall & 6 & 8216 & $1.20(0.79-1.82)$ & 0.40 & 0 \\
\hline \multicolumn{6}{|l|}{ Daily dose } \\
\hline Low dose & 2 & 1949 & $1.20(0.66-2.20)$ & 0.53 & 22.3 \\
\hline Medium dose & 2 & 4170 & $1.19(0.72-1.95)$ & 0.50 & 28.3 \\
\hline High dose & 2 & 2097 & $1.38(0.80-2.40)$ & 0.25 & 0 \\
\hline \multicolumn{6}{|l|}{ Duration } \\
\hline Less than 24 weeks & 1 & 1620 & $1.01(0.29-3.48)$ & 0.99 & \\
\hline At least 24 weeks & 5 & 6596 & $1.22(0.78-1.91)$ & 0.37 & 30.3 \\
\hline
\end{tabular}

Table 3 Subgroup analyses for new onset diabetes mellitus

\begin{tabular}{|c|c|c|c|c|c|}
\hline Subgroup title & No of trials & No of participants & Risk ratio $(95 \% \mathrm{Cl})$ & PValue & $I^{2}(\%)$ \\
\hline Overall & 8 & 33,340 & $1.04(0.88-1.15)$ & 0.95 & 0 \\
\hline \multicolumn{6}{|l|}{ Daily dose } \\
\hline Low dose & 1 & 444 & $0.71(0.03-17.41)$ & 0.84 & \\
\hline Medium dose & 2 & 26,941 & $1.00(0.87-1.14)$ & 0.99 & 0 \\
\hline High dose & 5 & 5955 & $1.16(0.53-2.54)$ & 0.71 & 0 \\
\hline \multicolumn{6}{|l|}{ Duration } \\
\hline Less than 1 year & 4 & 1844 & $0.70(0.16-2.98)$ & 0.63 & 0 \\
\hline At least 1 year & 4 & 31,496 & $1.01(0.88-1.15)$ & 0.91 & 0 \\
\hline
\end{tabular}

\section{Strengths and limitations}

This meta-analysis has some strengths. We followed the PRISMA statement and the recommendations of the Cochrane Collaboration to perform the study. In addition, we enrolled 17 RCTs with 43,430 subjects, so the combined results could be rigorous. However, our study also has several limitations. Firstly, the mean follow-up time of the included studies is around 30 weeks which is shorter than that of long-term observational studies, and this may result in no sufficient power to detect the observed excess risk. As Suissa et al. [39] reported that the incidence rate of diabetes was $14.2 / 1000 /$ year in the ICS users with asthma or COPD, the insufficient follow-up period may lead to negative results due to lack of power. When new long-term followed RCTs complete and publish their results, we will combine them with the current results to draw a more rigorous conclusion. Secondly, the type of ICS used in the majority of the enrolled studies was fluticasone, so the subgroup analysis that investigated the effects of different types of ICS on the risk of hyperglycemia could not be performed. Thirdly, we did not make a distinction between the studies that used a placebo or studies that compared to LABA only use.

\section{Conclusions}

Overall, use of ICS does not have an effect on the blood glucose and is not associated with the risk of new onset diabetes mellitus and diabetes progression in patients with COPD. Further RCTs exploring the association between ICS use and risk of hyperglycemia in COPD patients are still needed to verify our results of this analysis.

\section{Abbreviations \\ COPD: Chronic obstructive pulmonary disease; ICS: Inhaled corticosteroids; LABA: Long-acting beta-agonist; LAMA: Long-acting muscarinic antagonist; RCT: Randomized controlled trial; Cl: Confidence interval; PRISMA: Preferred Reporting Items for Systematic Reviews and Meta-Analysis; FEV1: Forced expiratory volume in 1 second; FF: Fluticasone furoate; VI: Vilanterol; SFC: Sal- meterol/fluticasone propionate; BUD: Budesonide; FM: Formoterol; BDP/FOR: Beclomethasone dipropionate/formoterol fumarate; UMEC: Umeclidinium; FSC: Fluticasone propionate/salmeterol.}

\section{Supplementary Information}

The online version contains supplementary material available at https://doi. org/10.1186/s12931-021-01789-7.

Additional file 1: Table S1. The PRISMA checklist. 
Additional file 2: Table S2. The detailed search strategies for Pubmed and Embase.

\section{Acknowledgements}

Not applicable.

\section{Authors' contributions}

XFP and GJW conceptualized and designed the study. XFP, LL and GJW wrote the manuscript. XFP and LL searched the literature and extracting data. BMF and ZJZ provided statistical assistance. All authors contributed to the review and approval of the final manuscript.

\section{Funding}

Not applicable

\section{Availability of data and materials}

All data generated or analysed during this study are included in this published article [and its additional files].

\section{Declarations}

\section{Ethics approval and consent to participate}

Not applicable.

\section{Consent for publication}

Not applicable.

\section{Competing interests}

The authors declare that they have no competing interests.

\section{Author details}

${ }^{1}$ Department of Pharmacy, The Affiliated Hospital of Southwest Medical University, 25 Taiping Street, Luzhou 646000, Sichuan, China. ${ }^{2}$ Department of Clinical Pharmacy, School of Pharmacy, Southwest Medical University, Luzhou 646000, China.

Received: 5 October 2020 Accepted: 29 June 2021

Published online: 08 July 2021

\section{References}

1. Mirza S, Clay RD, Koslow MA, Scanlon PD. COPD guidelines: a review of the 2018 GOLD report. Mayo Clin Proc. 2018;93(10):1488-502.

2. Anzueto A, Leimer I, Kesten S. Impact of frequency of COPD exacerbations on pulmonary function, health status and clinical outcomes. Int J Chron Obstruct Pulmon Dis. 2009;4:245-51.

3. Halpin DM, Miravitlles M, Metzdorf N, Celli B. Impact and prevention of severe exacerbations of COPD: a review of the evidence. Int J Chron Obstruct Pulmon Dis. 2017;12:2891-908.

4. Global Initiative for Chronic Obstructive Lung Disease. Global strategy for prevention, diagnosis, and management of chronic obstructive pulmonary disease; 2020. https://goldcopd.org. accessed May 26, 2020.

5. Yawn BP, Li Y, Tian H, Zhang J, Arcona S, Kahler KH. Inhaled corticosteroid use in patients with chronic obstructive pulmonary disease and the risk of pneumonia: a retrospective claims data analysis. Int J Chron Obstruct Pulmon Dis. 2013;8:295-304.

6. Arkhipov V, Arkhipova D, Miravitlles M, Lazarev A, Stukalina E. Characteristics of COPD patients according to GOLD classification and clinical phenotypes in the Russian Federation: the SUPPORT trial. Int J Chron Obstruct Pulmon Dis. 2017:12:3255-62.

7. Yang M, Du Y, Chen H, Jiang D, Xu Z. Inhaled corticosteroids and risk of pneumonia in patients with chronic obstructive pulmonary disease: a meta-analysis of randomized controlled trials. Int Immunopharmacol. 2019;77:105950

8. Loke YK, Cavallazzi R, Singh S. Risk of fractures with inhaled corticosteroids in COPD: systematic review and meta-analysis of randomised controlled trials and observational studies. Thorax. 2011;66(8):699-708.
9. Yang M, Zhang Y, Chen H, Lin J, Zeng J, Xu Z. Inhaled corticosteroids and risk of upper respiratory tract infection in patients with asthma: a metaanalysis. Infection. 2019;47(3):377-85.

10. Price DB, Voorham J, Brusselle G, Clemens A. Inhaled corticosteroids in COPD and onset of type 2 diabetes and osteoporosis: matched cohort study. 2019;29(1):38.

11. Saeed MI, Eklöf J, Achir I, Sivapalan P, Meteran H, Løkke A, et al. Use of inhaled corticosteroids and the risk of developing type 2 diabetes in patients with chronic obstructive pulmonary disease. Diabetes Obes Metab. 2020;22(8):1348-56.

12. Dendukuri N, Blais L, LeLorier J. Inhaled corticosteroids and the risk of diabetes among the elderly. Br J Clin Pharmacol. 2002;54(1):59-64.

13. Lee CH, Kim J, Jang EJ, Lee JH, Kim YJ, Choi S, et al. Inhaled corticosteroids use is not associated with an increased risk of pregnancy-induced hypertension and gestational diabetes mellitus: two nested case-control studies. Medicine (Baltimore). 2016;95(22):e3627.

14. O'Byrne PM, Rennard S, Gerstein H, Radner F, Peterson S, Lindberg B, et al. Risk of new onset diabetes mellitus in patients with asthma or COPD taking inhaled corticosteroids. Respir Med. 2012;106(11):1487-93.

15. Bhatt SP, Dransfield MT, Cockcroft JR, Wang-Jairaj J, Midwinter DA, Rubin $\mathrm{DB}$, et al. A randomized trial of once-daily fluticasone furoate/vilanterol or vilanterol versus placebo to determine effects on arterial stiffness in COPD. Int J Chron Obstruct Pulmon Dis. 2017;12:351-65.

16. Dransfield MT, Bourbeau J, Jones PW, Hanania NA, Mahler DA, Vestbo $J$, et al. Once-daily inhaled fluticasone furoate and vilanterol versus vilanterol only for prevention of exacerbations of COPD: two replicate double-blind, parallel-group, randomised controlled trials. Lancet Respir Med. 2013;1(3):210-23.

17. Asai K, Kobayashi A, Makihara Y, Johnson M. Anti-inflammatory effects of salmeterol/fluticasone propionate $50 / 250$ mcg combination therapy in Japanese patients with chronic obstructive pulmonary disease. Int J Chron Obstruct Pulmon Dis. 2015;10:803-11.

18. Lipson DA, Barnhart F, Brealey N, Brooks J, Criner GJ, Day NC, et al. Oncedaily single-inhaler triple versus dual therapy in patients with COPD. N Engl J Med. 2018:378(18):1671-80.

19. Wedzicha JA, Banerji D, Chapman KR, Vestbo J, Roche N, Ayers RT, et al. Indacaterol-glycopyrronium versus salmeterol-fluticasone for COPD. N Engl J Med. 2016;374(23):2222-34.

20. Moher D, Shamseer L, Clarke M, Ghersi D, Liberati A, Petticrew M, et al. Preferred reporting items for systematic review and meta-analysis protocols (PRISMA-P) 2015 statement. Syst Rev. 2015;4(1):1.

21. Cumpston M, LiT, Page MJ, Chandler J, Welch VA, Higgins JP, Thomas J. Updated guidance for trusted systematic reviews: a new edition of the Cochrane Handbook for Systematic Reviews of Interventions. Cochrane Database Syst Rev. 2019;10:142.

22. Zhong N, Wang C, Zhou X, Zhang N, Humphries M, Wang L, et al. LANTERN: a randomized study of QVA149 versus salmeterol/fluticasone combination in patients with COPD. Int J Chron Obstruct Pulmon Dis. 2015;10:1015-26

23. Kerwin EM, Scott-Wilson C, Sanford L, Rennard S, Agusti A, Barnes N, et al. A randomised trial of fluticasone furoate/vilanterol $(50 / 25 \mu \mathrm{g} ; 100 / 25 \mu \mathrm{g})$ on lung function in COPD. Respir Med. 2013;107(4):560-9.

24. Maltais F, Ostinelli J, Bourbeau J, Tonnel AB, Jacquemet N, Haddon J, et al. Comparison of nebulized budesonide and oral prednisolone with placebo in the treatment of acute exacerbations of chronic obstructive pulmonary disease: a randomized controlled trial. Am J Respir Crit Care Med. 2002;165(5):698-703.

25. Martinez FJ, Boscia J, Feldman G, Scott-Wilson C, Kilbride S, Fabbri L, et al. Fluticasone furoate/vilanterol $(100 / 25 ; 200 / 25 \mu \mathrm{g})$ improves lung function in COPD: a randomised trial. Respir Med. 2013;107(4):550-9.

26. Sharafkhaneh A, Southard JG, Goldman M, Uryniak T, Martin UJ. Effect of budesonide/formoterol pMDI on COPD exacerbations: a double-blind, randomized study. Respir Med. 2012;106(2):257-68.

27. Siler TM, Nagai A, Scott-Wilson CA, Midwinter DA, Crim C. A randomised, phase III trial of once-daily fluticasone furoate/vilanterol 100/25 $\mu \mathrm{g}$ versus once-daily vilanterol $25 \mu \mathrm{g}$ to evaluate the contribution on lung function of fluticasone furoate in the combination in patients with COPD. Respir Med. 2017;123:8-17.

28. Vogelmeier CF, Bateman ED, Pallante J, Alagappan VK, D'Andrea P, Chen H, et al. Efficacy and safety of once-daily QVA149 compared with twice-daily salmeterol-fluticasone in patients with chronic obstructive pulmonary 
disease (ILLUMINATE): a randomised, double-blind, parallel group study. Lancet Respir Med. 2013;1 (1):51-60.

29. Vestbo J, Anderson JA, Brook RD, Calverley PM, Celli BR, Crim C, et al. Fluticasone furoate and vilanterol and survival in chronic obstructive pulmonary disease with heightened cardiovascular risk (SUMMIT): a doubleblind randomised controlled trial. Lancet. 2016;387(10030):1817-26.

30. Wedzicha JA, Singh D, Vestbo J, Paggiaro PL, Jones PW, Bonnet-Gonod F, et al. Extrafine beclomethasone/formoterol in severe COPD patients with history of exacerbations. Respir Med. 2014:108(8):1153-62.

31. Zheng J, de Guia T, Wang-Jairaj J, Newlands AH, Wang C, Crim C, et al. Efficacy and safety of fluticasone furoate/vilanterol (50/25 mcg; 100/25 $\mathrm{mcg} ; 200 / 25 \mathrm{mcg}$ ) in Asian patients with chronic obstructive pulmonary disease: a randomized placebo-controlled trial. Curr Med Res Opin. 2015;31(6):1191-200.

32. GlaxoSmithKline. A 16-Week Study to Evaluate the Effect of Advair DISKUS $^{\text {TM }}$ 250/50mcg on Arterial Stiffness in Subjects With Chronic Obstructive Pulmonary Disease (COPD). Available from: https://ClinicalTrials.gov/ show/NCT00857766. accessed 25 May, 2020.

33. GlaxoSmithKline, Parexel. A Comparative Study Between Fluticasone Furoate/Umeclidinium/Nilanterol (FF/UMECNI) Single Inhaler Triple Therapy Versus Tiotropium Monotherapy in Subjects With Chronic Obstructive Pulmonary Disease (COPD). Available from: https://ClinicalTr ials.gov/show/NCT03474081. Accessed 25 May, 2020.
34. Global Initiative for Asthma. Global Strategy for Asthma Management and Prevention, 2020. Available from: https://ginasthma.org/wp-content/ uploads/2020/06/GINA-2020-report_20_06_04-1-wms.pdf. Accessed 25 May, 2020.

35. Rogala B, Bożek A, Gluck J. Is there a relationship between asthma and diabetes? J Asthma. 2019;1-7.

36. Kaul K, Apostolopoulou M, Roden M. Insulin resistance in type 1 diabetes mellitus. Metabolism. 2015;64(12):1629-39.

37. Borsi SH, Rashidi H, Shaabanpour M, Raji H. The effects of inhaled corticosteroid on insulin sensitivity in asthmatic patients. Monaldi Arch Chest Dis. 2018;88(1):892

38. Allen DB, Bielory L, Derendorf H, Dluhy R, Colice GL, Szefler SJ. Inhaled corticosteroids: past lessons and future issues. J Allergy Clin Immunol. 2003;112(3 Suppl):S1-40.

39. Suissa S, Kezouh A, Ernst P. Inhaled corticosteroids and the risks of diabetes onset and progression. Am J Med. 2010;123(11):1001-6.

\section{Publisher's Note}

Springer Nature remains neutral with regard to jurisdictional claims in published maps and institutional affiliations.
Ready to submit your research? Choose BMC and benefit from:

- fast, convenient online submission

- thorough peer review by experienced researchers in your field

- rapid publication on acceptance

- support for research data, including large and complex data types

- gold Open Access which fosters wider collaboration and increased citations

- maximum visibility for your research: over $100 \mathrm{M}$ website views per year

At BMC, research is always in progress.

Learn more biomedcentral.com/submissions 